\title{
Development of Composites Sandwich Structures Using a Core Cork
}

\author{
D. Regaçon ${ }^{1}$ and A. Garay ${ }^{2}$ \\ 1. UFN, University Franciscana Santa Maria, Santa Maria, RS 97015-001 Brazil \\ 2. PPGEM, Federal University of Rio Grande do Sul (UFRGS), Porto Alegre, RS 91501-970, Brazil
}

\begin{abstract}
Sandwich structures are comprised of two external faces/skins (usually made of synthetic fiber/resin) and a core between them, being lightweight and with high stiffness. The employment of composite materials such as engineering materials has achieved more space in various segments of the industry, due to the following properties found: low density, stiffness, resistance to abrasion, impact and corrosion developed along the technological advancement of materials. This study aimed to develop a composite structure sandwich with cork core using in the face resin unsaturated polyester and glass fiber material, in order to obtain a final material with improved mechanical and physical properties compared to a conventional composite, without core. The samples were obtained by pressing process for different volume percentage of glass fiber in order to evaluate the influence of this parameter on the behavior of the material. The different samples were mechanically analyzed using the tests by tensile, bending and hardness, revealing high efficiency, except for the bending test in which the sandwich composite showed lower values compared to the composite standard. It was also performed to test water absorption, thermal and acoustic insulation test achieving satisfactory results and proving the effectiveness of cork in the search for materials with insulating characteristics, thus enabling the use of cork as a raw material for this class of materials contributing to sustainability and helping to generate values and innovation. In addition, it functions as a great thermal and acoustic insulation.
\end{abstract}

Key words: Composite sandwich, cork core, mechanical and physical properties, thermal and acoustic properties.

\section{Introduction}

The sandwich composite panels were developed during World War II by the need for lighter materials and high rigidity, these structures have been developed over time and gaining more demanding applications [1]. A sandwich panel consists of two skins, or facings, with a core material in between, and it basically works like an I-beam. The skins take up the normal strains and give the structure a hard wearing surface [1], being sometimes built with a reinforcement made of glass or carbon fibers and a polymeric resin (e.g. epoxy or vinyl ester) as matrix [2]. The core material must have adequate shear stiffness to absorb applied shear forces, distributing them over a large area, and low specific weight, being

Corresponding author: André Cechin Garay, Ph.D. in materials science and technology, research field: composites materials. joined to the faces mechanically or by adhesive bonding. Among the range of cores available the most common are wood and cork no synthetic, and PVC, PET, PU, PS, PET and PVC foam cores synthetic.

Cork is a biological tissue, non-toxic and renewable resources, recyclable, coating obtained from the trunk of the trees. The tree of Sobreiro (Quercus suber L.) is the main feature of commercial cork extraction, although not the only species of the genus Quercus trees from which to get the cork [3]. It presents interesting physical and chemical properties which lead to more demanding applications. It is a practically impermeable material to liquids and gases, with high lightness, low thermal and electrical conductivity and a great acoustic absorber and vibration. The material is harmless, which has almost no lateral expansion when subjected to compression between Cork features that highlight the chemical and biological stability and good fire resistance [4]. 
Among various types of matrices, the polyester resin dominates the market and is within the concept of thermoset matrix and is the most used in the production of composites by aligning performance and cost characteristics. The advanced properties and structural composite applications are the result of variation of stacking architecture, the nature of the resins and fibers and manufacturing process [1]. The curing reaction of the polyester resin proceeds slowly, due to mobility of small molecules constituents, necessitating heating the resin by applying electromagnetic radiation, or by adding reaction accelerators and catalysts. Then the free radical catalyst attacks the unsaturation in the polyester or the low molecular weight monomers, starting the polymerization reaction chain, forming a rigid three-dimensional network [5].

The fiberglass (GF) also is highlighted the use of reinforcements in composite materials of polymer matrix, mainly because it is low cost, high tensile strength and high chemical inertia. Much is due to the origin and abundance of the raw material used to manufacture the material. When the aggregate composite $V_{f}$ (fiber volume) is associated with relatively low elastic modulus, self abrasiveness and low fatigue resistance [5].

As knowledge about the potential of cork, be limited and little explored, this work aimed to study this raw material as core sandwich composite, in search of mechanical properties and improved final physical, contributing to sustainability and to the generation of values and innovation.

\section{Experimental}

The study composite was obtained by the compression process in a stainless steel mold (270 $\mathrm{mm} \times 170 \mathrm{~mm} \times 4 \mathrm{~mm}$ ), which were molded test specimens (CP) sandwich composite using as core cork and as the material of the face GF (oriented $0^{\circ}$ and $90^{\circ}$ ) and unsaturated isophthalic polyester resin. Also was molded a standard $\mathrm{CP}$ in order to evaluate the effectiveness of the core in material properties. The process of compression the $\mathrm{CP}$ was held at the Ceramic Materials Laboratory of Franciscan University.

For the standard specimen molding, called CP A, the percentage of each constituent has been stipulated, with $20 \%$ glass fiber reinforcement volume $\left(\% V_{f}\right)$ and $80 \%$ of the resin volume $\left(\% V_{r}\right)$ by relationship of the mold volume and the density of the raw material.

To obtain the CP it was necessary the preparation of the mold with a release polyvinyl acrylate (PVA) and after this weigh each constituent (Resin, Fiber and Cork). The preparation of the resin gave himself by adding $1 \%$ of mass Butanox APK initiator and 1\% Cobalt accelerator, for polymerization to occur. The constituents were arranged in the mold interposing resin layers and GF, then passing by uniaxial pressing process Hydraulic Press Bovenau P10 ST, a force of 4 tons in a 24 hours period of cure and a post cure in an oven at temperature of $80^{\circ} \mathrm{C}$ for 24 hours as shown in Fig. 1.

To obtain the CP with cork core, they are stipulated numbers GF layers interleaved with a core layer of cork agglomerate, with a thickness of $1 \mathrm{~mm}$ as shown in Table 1. The compression process followed the same methodology CP pattern with the same volume of resin, initiator and accelerator.

Characterization in order to investigate the mechanical properties of the material developed in 6 CPs which were submitted tension, following the ASTM D3039 M-08, with test speed of $5 \mathrm{~mm} / \mathrm{min}$. It was also performed three-point bending test following ASTM D790-97. The mechanical tests were performed on universal machine EMIC DL10000 trials at the University Center of Testing Laboratory Franciscan. In order to evaluate the resistance against perforation and scratches at low speed, the PLCs have been subjected to Barcol hardness test durometer Barcol the Bareiss model II BS 61, which were carried out 10 measurements per sample according to ASTM D2583. The test was conducted in Polymeric Materials Laboratory (Lapol) of the Federal University 

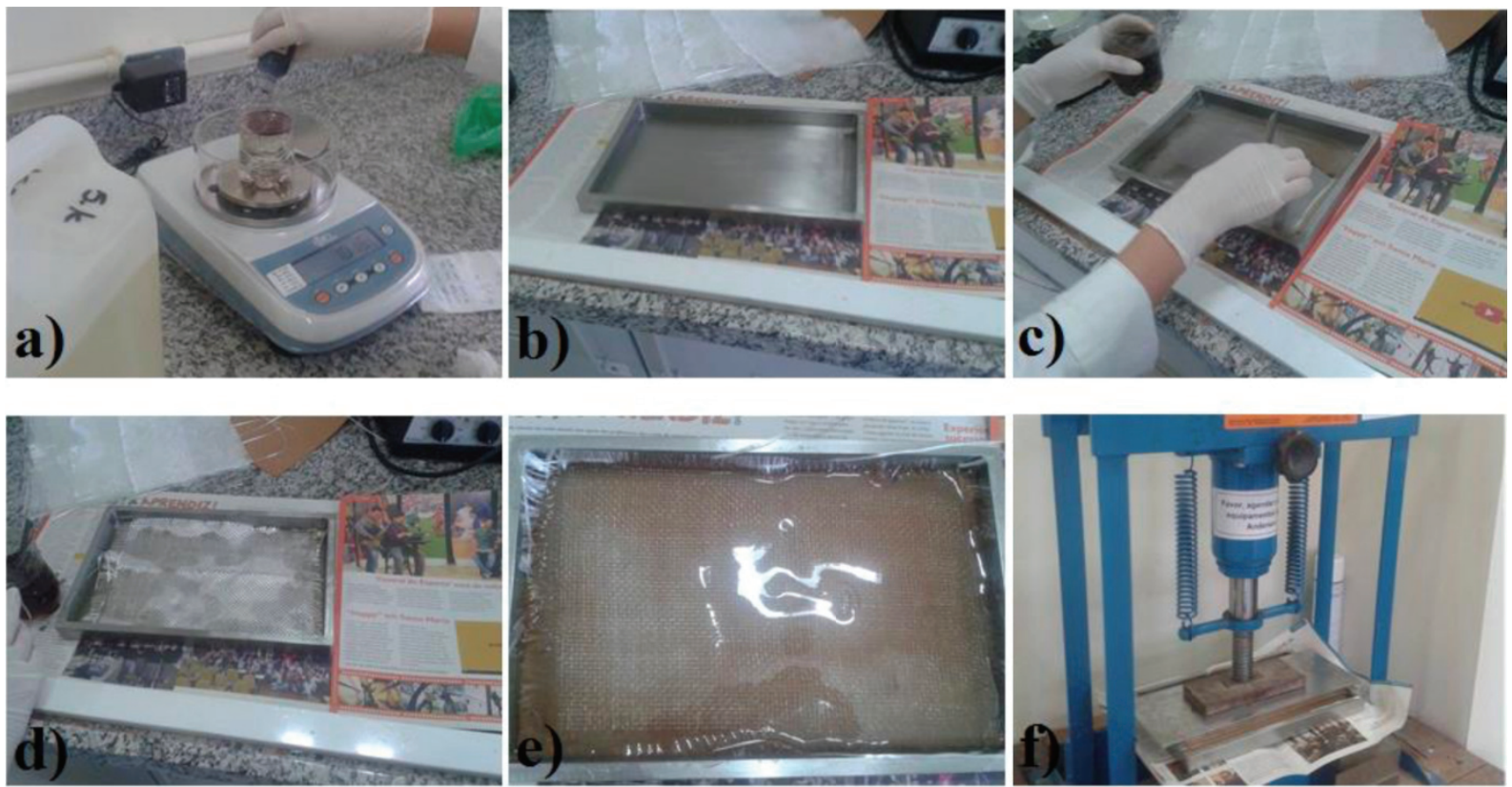

Fig. 1 Steps molding, (a) resin preparation, (b) mold release agent, (c) first resin layer, (d) FV layer, (e) mold ready for the pressing e (f) part compression.

Table 1 Composition of sandwich composite panels.

\begin{tabular}{llllll}
\hline CP & Fiber layer & Cork core & \% Resin & \% Initiator in the volume of the resin & \% Accelerator in the volume of the resin \\
\hline A & 7 & 0 & 80 & 1 & 1 \\
B & 4 & 1 & 80 & 1 & 1 \\
C & 6 & 1 & 80 & 1 & 1 \\
D & 8 & 1 & 80 & 1 & 1 \\
\hline
\end{tabular}

of Rio Grande do Sul (UFRGS).

Water absorption test was performed following ASTM D570-98, where the CPs were in an oven for a period of 24 hours $(50 \pm 3){ }^{\circ} \mathrm{C}$, cooled in a desiccator and weighed on an analytical balance to obtain it that is dry weight. After the samples were immersed in distilled water and maintained at $(23 \pm 3){ }^{\circ} \mathrm{C}$ for 24 hours to obtain a moist mass which was removed excess water with a paper towel and reweighed.

The immersion and weighing process is repeated after one week until the average was less than $1 \%$, according to Eq. (1).

$$
A A \%=\frac{M u-M s}{M s} \cdot 100
$$

where, $A A$ is the water absorption percentage content, Ms is the dry mass $\mathrm{Mu}$ and, the wet sample weight.

In order to investigate the acoustic capacity of the material, boxes were made similar to a cube bottomless $(170 \mathrm{~mm} \times 130 \mathrm{~mm} \times 130 \mathrm{~mm})$ and an upper opening $15 \mathrm{~mm}$ in diameter. The acoustic analysis was given from the issuance of a continuous noise picked up by the sound level meter Sound Level Meter RS-232/Datalogger, introduced in the upper opening of the CPs and compared with the reading of decibels on the outside of the CPs, thus obtaining the ability to acoustic insulation composite studied, following the methodology of Ref. [6].

To evaluate the studied material as the thermal capacity, they used the same CPS acoustic conductivity test. These were loaded with the opening facing downwards, resting on a plate of expanded polystyrene (EPS) $50 \mathrm{~mm}$ thick, so there is no interference temperature of the support surface. It was introduced to the stem of a Digital Thermometer Incoterm model 7665.020.00 the hole in the top of the 
box face and another on the outside to determine the temperature differential $\mathrm{T} 1$ and $\mathrm{T} 2$ and then started to heat emission from a source (heating mondial term ceramic a-05) at a distance of $50 \mathrm{~cm}$ from the CP by a 30 minutes period, as shown in Fig. 2, temperatures were taken at 7 different times during the test time, adapting the methodology [6].

\section{Results and Discussion}

Study behavior in tension of the developed material can be seen in Fig. 3. Sample A, which has no cork, performs well when subjected to traction, yet lower than sample D, having a higher nucleus $V_{f}$ and cork.
With reference to the standard PC without cork, sample B showed a performance approximately $62.35 \%$ to $81.22 \%$ of sample C and sample D $116.36 \%$ less than default sample. We can see a linearity in tensile strength, the material studied on the number of layers of $\mathrm{PV}$, which is explained by high resistance property to fiberglass pull together with their arrangement in the form of tissue, increasing resistance in requests in the direction of the fibers [1]. The results are within expected values, because the composites $\mathrm{B}$ and $\mathrm{C}$ have lower $V_{f} \% \mathrm{~A}$ and $\mathrm{D}$ at this lower tensile strength values. As will increase the number of layers and $V_{f}^{\mathrm{o}} \%$ $\mathrm{B}$ to $\mathrm{D}$, the tensile strength increases accordingly.

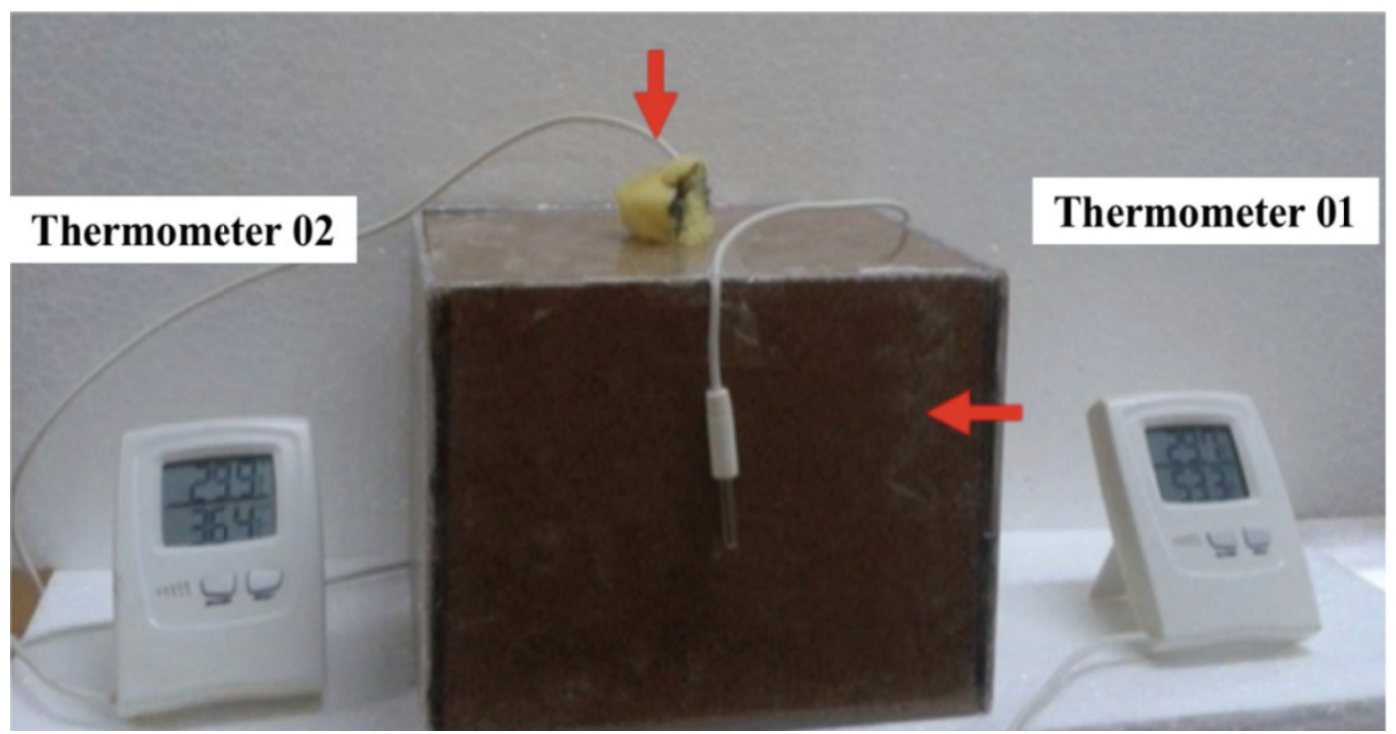

Fig. 2 System for determining the thermal capacity.

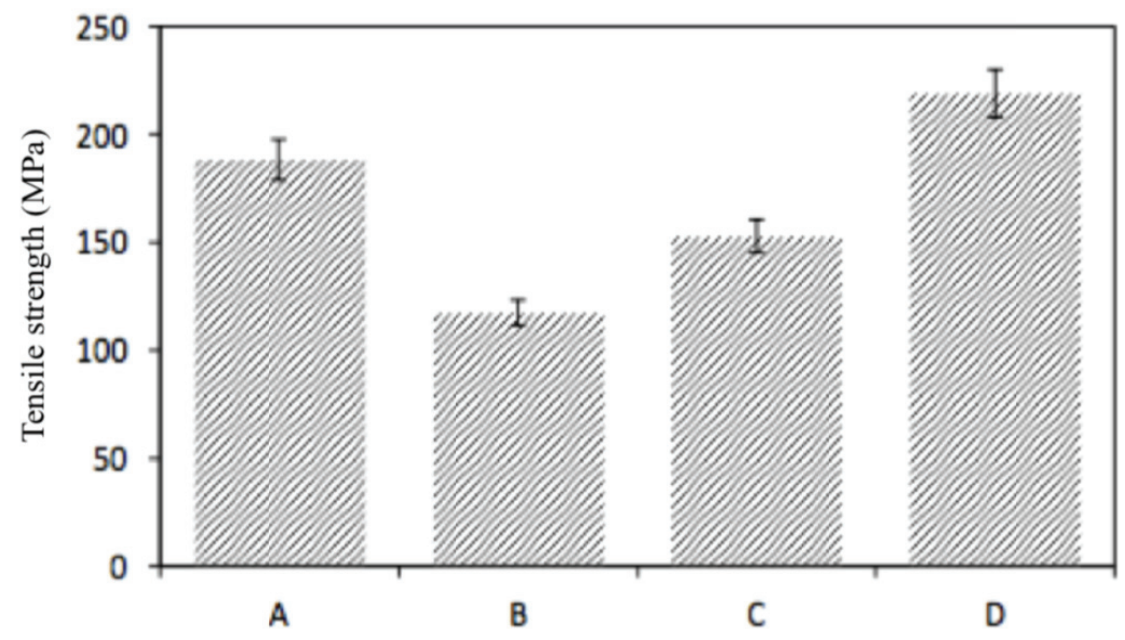

Fig. 3 Tensile strength of the different specimens. 
The study of behavior in bending when a panel or sandwich beam is subjected to bending tests 3 points, its behavior resembles a chevron I-shaped, where the faces act as the flange supporting the cutting forces and the core materials act as the shear web beams. The performance of the developed material can be seen in Fig. 4. Samples with cork core obtained maximum values of voltage under load in bending lower than the standard sample. This behavior can be explained by the characteristics of high deformability and low creep resistance presented by the cork [7], and the core has a lower shear strength. As expected, the fiber volume directly affects the tensile strength, so that the higher the percentage of $\mathrm{PV}$, the greater the resistance to bending before the composite failure occurs.

The average Barcol hardness values measured on the surface of the composites are shown in Fig. 5 where we note an increase in hardness by adding more layers of PV. Related to obtained Barcol hardness, the standard sample showed hardness $28.82 \%$ higher than the sample $\mathrm{B}$, which has the lowest $V_{f} \%$ of the samples. The efficiency of the samples $\mathrm{C}$ and $\mathrm{D}$ are superior to the standard sample, $\mathrm{C}$ being more efficient and $11.67 \%$ D $17.29 \%$ showed hardness higher

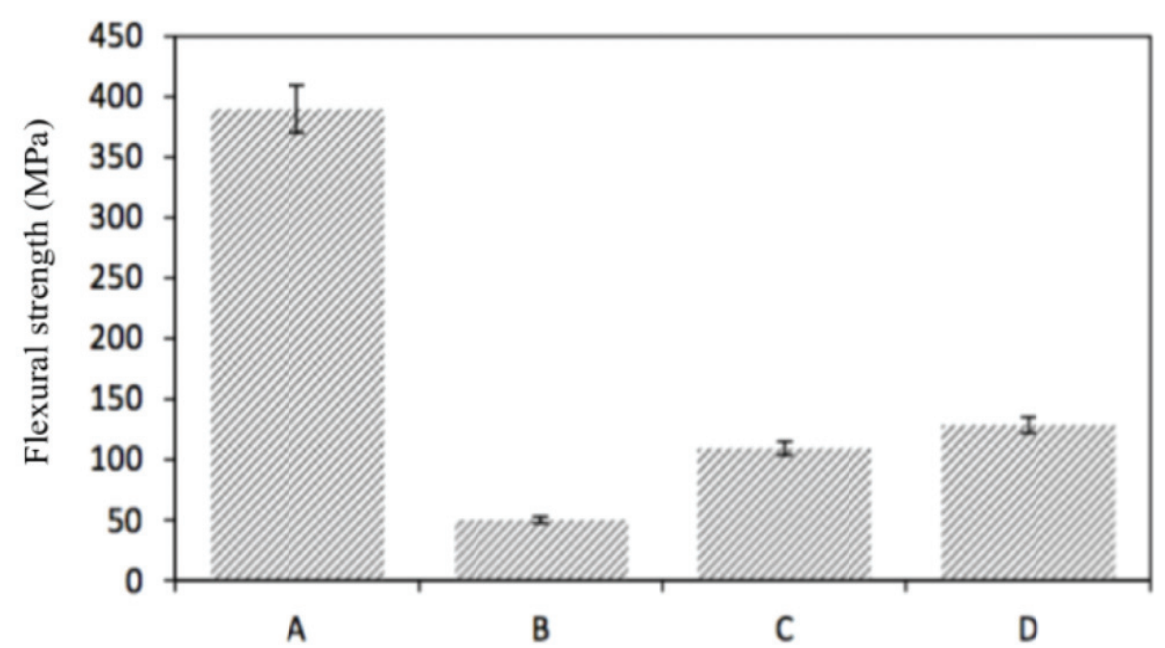

Fig. 4 Flexural strength of the different specimens subjected to the test.

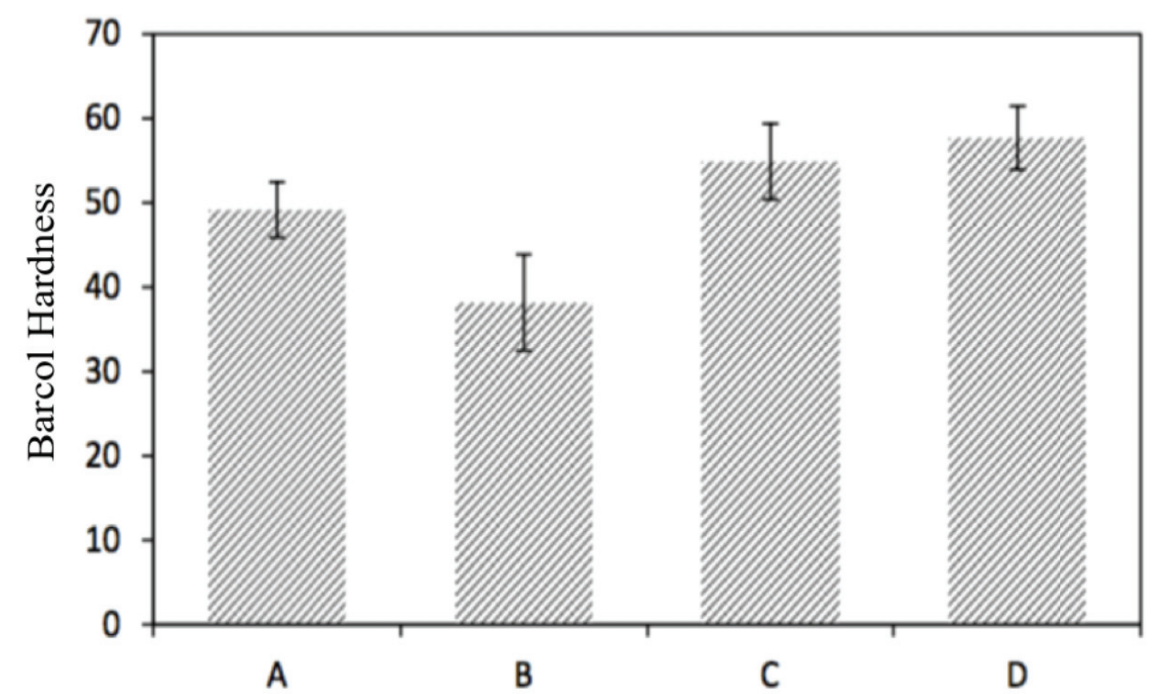

Fig. 5 Comparative test Barcol Hardness. 
than the sample A. The present values associated increased mechanical strength also studied the $\% V_{f}$, inorganic material with high hardness mainly on the surface of the face, as consisted [2]. The knowledge and the search for increasing the hardness of composite materials become important in order to withstand shocks and scratches at low speed, preventing perforation of the face for no core exposure to moisture.

Study of water absorption was determined by the water uptake of the different samples analyzed after 24 hours of immersion in distilled water and 168 hours of immersion, when the difference of the measurements was less than $1 \%$. The results are shown in Table 2. The sample molded only FV and resin showed a lower percentage of absorption compared to samples B and D, but still higher than sample $\mathrm{C}$ and had the best performance in immersion. As Ref. [7], throughout the trial it was identified that the permeation of water occurs more intensely in the regions of machining to shape the CPs, as shown in
Fig. 6, where the edges of the fibers are exposed. To minimize this effect, the sealing of these points with the resin itself would be required.

It is of great importance to study the hygroscopic capacity of the material, especially when using a raw material of organic origin, since water absorption can lead to change in strength properties as well as thermal conductivity properties, because when absorbed moisture replaces the air that increases the thermal conductivity value of materials.

The sound for acoustic performance measures was to feature a constant noise. The values obtained are shown in Table 3, where it is noted an increasing reduction in the number of layers of PV and greater efficiency in sandwich composite samples, which demonstrates the feasibility of acoustic material developed. All samples sandwich composite showed greater effectiveness in soundproofing test when compared to standard sample justified by corkboard features as its low density and its high porosity content, with the acoustic insulation reference values

Table 2 Determination of water absorption.

\begin{tabular}{|c|c|c|c|c|c|}
\hline$\overline{\mathrm{CP}}$ & Initial weight $(\mathrm{g})$ & Weight after $24 \mathrm{hrs}$ of immersion (g) & $\%$ AA & Weight after 168 hrs of immersion $(\mathrm{g})$ & $\%$ AA \\
\hline $\bar{A}$ & 17.235 & 17.637 & 2.334 & 18.020 & 0.211 \\
\hline $\mathrm{B}$ & 16.055 & 16.558 & 3.133 & 16.694 & 0.820 \\
\hline $\mathrm{C}$ & 16.517 & 16.798 & 1.701 & 16.812 & 0.083 \\
\hline D & 16.908 & 17.345 & 2.584 & 17.445 & 0.581 \\
\hline
\end{tabular}

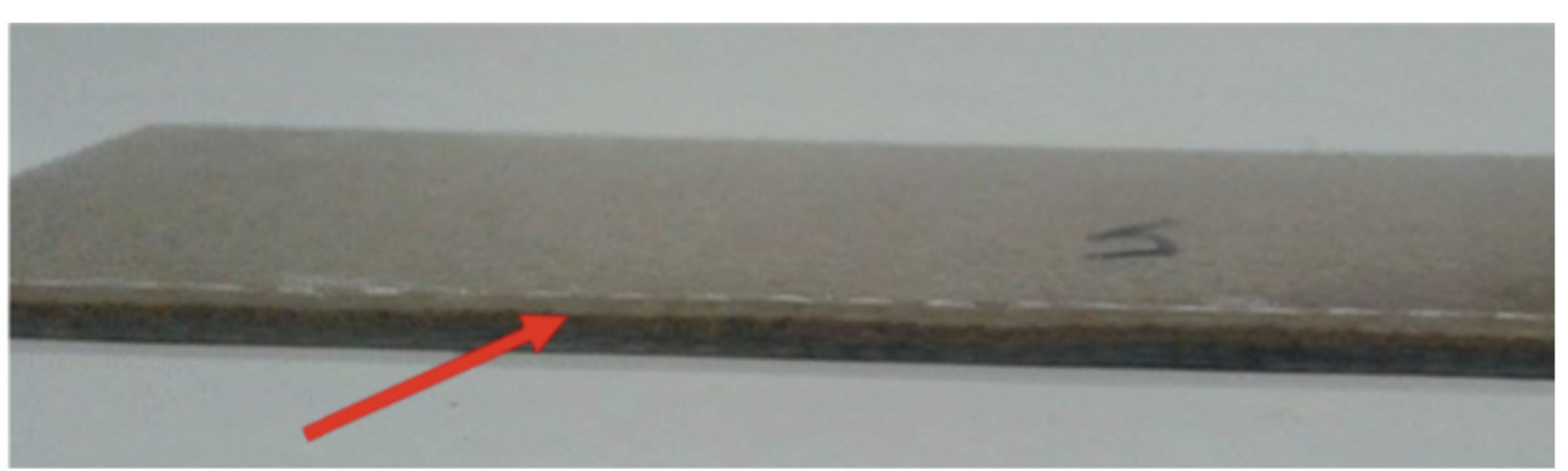

Fig. 6 Edge the machined of specimens.

Table 3 Material performance acoustic conductivity test.

\begin{tabular}{lllll}
\hline CP & A & B & C & D \\
\hline Noise produced $85.6 \mathrm{~dB}$ & 77.13 & 75.06 & 74.8 & 73.53 \\
Reduction in \% & 9.89 & 12.31 & 12.62 & 14.10 \\
\hline
\end{tabular}




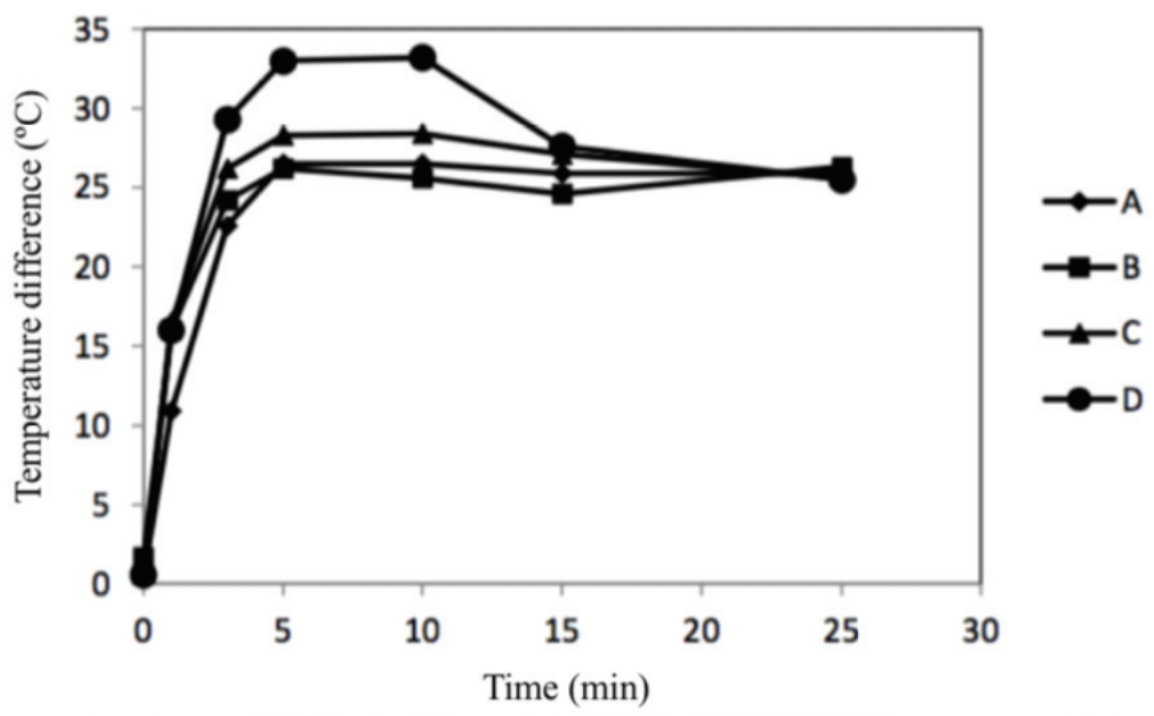

Fig. 7 Thermal conductivity.

its low density and its high porosity content, with the sound insulation reference value of $1.2^{\prime} 10 \mathrm{~kg} / \mathrm{m} . \mathrm{s}$ [8]. That all samples were being analyzed is in an application for noise mitigation which would make the salubrious environment, considering the requirements of NR 15 for a display of a period of 8 hours.

Study of thermal capacity research results of thermal insulation capacity of the material studied is shown in Fig. 7. The record temperatures were made before turning on the heater and after 6 predetermined times, the internal and external thermometer. As expected, the cork performed well as a thermal insulator, when incorporated into the composite developed. The CP default obtained temperature gradient values similar to the test body $\mathrm{B}$, and considering only the samples with cork, performance was gradually related to the amount of FV samples. Thus the CP D showed the greater temperature differential reaching a reduction of approximately 54\% temperature time of 10 minutes, the sample $\mathrm{C}$ reached a $50 \%$ of the captured temperature CP on the outside between 5 and 10 minutes.

\section{Conclusions}

According to the results achieved in this study, it is concluded that the sandwich composites with cork core have developed mechanical and physical properties different from the usual composites, without cork. According to the results of tensile, bending and Barcol hardness, a significant influence is noted GF percentage increase in the mechanical properties. It is also possible to show the insulating properties of cork features, both insulated assay where it has a great advantage in addition to the core, as in the assay insulation where the combination of the cork core with GF percentage resulted in reduction of the thermal conductivity of the final material [10]. On the whole, were show up thermal insulation and acoustic characteristics of the studied material. Making it feasible to use in systems requiring noise attenuation and heat as well as machinery and equipment enclosure.

\section{References}

[1] Saha, M. C., Kabir, E., and Jeelani, S. 2008. "Study of Debond Fracture Toughness of Sandwich Composites with Nano Phased Core." Mater Lett 62 (4-5): 567-70.

[2] Mitra, N. 2010. “A Methodology for Improving Shear Performance of Marine Grade Sandwich Composites: Sandwich Composite Panel with Shear Key." Compos Struct 92 (5): 1065-72.

[3] Garay, A. C. 2010. "Efeito da adição de carbonato de cálcio em compósitos poliméricos moldados por RTM e RTM light." Dissertação (obtenção de título de mestre), Universidade Federal do Rio Grande do Sul, Porto 
Alegre,

[4] Garay, A. C., Sampert, F., Moreira, V., Souza, J. A., and Amico, S. C. 2011. "Avaliação de diferentes núcleo e faces em materiais compósitos sanduíche para aplicações marítimas.” In Congresso Brasileiro de Polímeros, 11, 2011, Campos do Jordão-SP.

[5] Garay, A. C. 2012. "Análise das propriedades de compósitos estruturais tipo sanduíche moldados por RTM light." 74 f. Tese (Exame de qualificação de Doutorado) - Universidade Federal do Rio Grande do Sul, Porto Alegre, 2012.

[6] Marinucci, G. 2011. Materiais Compósitos Poliméricos. São Paulo: Artiliber Editora, 333.

[7] Mestre, A., and Vogtlander, J. 2013. "Ecco-efficient
Value Creation of Cork Products: An LCA-Based Method for Design Intervention." Journal of Cleaner Production 57: 101-14.

[8] Neto, F. L., and Pardini, L. C. 2006. Compósitos Estruturais: Ciência e Tecnologia. São Paulo: Edgard Blücher, 336.

[9] Sen, A., Bulcke, J. V., Defoirdt, N., Acker, J. V., and Pereira, H. 2014. "Thermal Behaviour of Cork and Cork Components." Thermochimica Acta 582: 94-100.

[10] Silva, B. D., Costa, H. P., Santos, E. W. F., and Cabral, M. F. F. 2008. "Análise da capacidade de isolamento termo-acústico do concreto leve empregado como argamassa de revestimento.” In: Congresso Brasileiro do Concreto, 50, 2008, São Paulo. 